\title{
Method for calculating the maximum number of railway cars in a cut
}

\author{
Aleksandr Klimov ${ }^{1, *}$, Anton Gunbin ${ }^{1}$, Dmitry Osipov ${ }^{1}$, and Pavel Burdyak ${ }^{1}$ \\ ${ }^{1}$ Siberian Transport University, 630049 Novosibirsk, Russia
}

\begin{abstract}
A shunting process in hump yards has a number of technical and technological constraints, one of which is the maximum permissible number of cars in a cut. This constraint increases the number of cuts, time of shunting, operating costs of car handling operations in a railways network, while reducing the safety level of classification. The purpose of the paper is to maximize the handling capacity of hump yards by reasonably increasing the permissible length of cuts. The current methods of calculation do not take into account some features of classification operations with long cuts of cars. The proposed method is based on probability calculations and simulation modeling of the shunting process in hump yards. The authors identified the critical factors limiting the maximum permissible number of cars in a cut and developed a method to determine this limitation.
\end{abstract}

\section{Introduction}

Car handling operations in railway networks around the world are concentrated in classification yards. Technical and technological constraints of hump yards are connected with safety requirements. One of such constraints in railway networks of Russia and other countries is the maximum permissible number of cars in a cut. This increases the time of shunting and reduces the handling capacity of a hump yard.

The subject of the study is a controlled rolling-down process for cuts of varied length. The research focuses on determining the maximum number of cars in a cut.

The existing method for calculating the maximum number of cars in a cut used by classification yards of Russia's common railway network is based on energy parameters of a cut rolling down from the hump [1]. The total power of retarder positions in a decreasing part of the hump and in the classification yard as well as the permissible entry speed of a multi-car cut to the classification yard are considered as constraints. Specialists calculate these parameters by analytical methods, without taking into account some features of calculations for hump yard operations, which are described in the applicable standards [23].

Rolling-down parameters are calculated subject to forces of resistance to train movement. Different countries of the world use several types of uncontrolled resistance forces to calculate parameters of hump yard operations. These include net resistance,

\footnotetext{
* Corresponding author: aklimov@,ngs.ru
} 
resistance from the environment and wind, resistance from railway switches and curves, snow and frost, etc. [4-13].

Studies [14-15] describe a process of passing long cuts through a hump crest and confirm that the total specific energy stored by these cuts decreases with a decrease in the center of mass relative to the hump crest.

In general, the existing methods for calculating the maximum number of cars in a cut can be used to quickly determine a required parameter for any hump yard. However, there are some controversial issues in the calculation. Several empirical coefficients and experience of similar calculations in different countries make it necessary to develop a new method for determining the maximum permissible number of cars in a cut.

The calculations made in this study are aimed at increasing the handling capacity of hump yards to reduce operating costs of car handling operations, while reducing the safety level of the classification process.

\section{Research method}

The existing calculation method [1] has the following drawbacks:

1. Acceleration of gravity $g=9.8 \mathrm{~m} / \mathrm{s}^{2}$ is used in calculation. However, the method does not take into account the inertia of rotating parts of cars, which is expressed as $g^{\prime}$ in conventional calculations for hump yard operations.

2. The method does not take into account the energy loss from overcoming uncontrolled forces of resistance to the movement by the cut, as well as the dependence of the maximum number of cars in the cut on its weight.

3. The method does not specify requirements for environmental parameters to be calculated, and necessary conditions for these calculations.

4. The shunting speed $v_{o}$ is proposed to be taken from local guidelines. The Design Rules and Regulations for Shunting Facilities [2] give specific instructions for determining the shunting speed depending on the capacity of a hump yard and tasks to be solved.

5. The total specific energy stored by a cut of cars includes $\Delta h-$ the maximum difference between a hump crest and a yard retarder position. For long multi-car cuts, the center of mass is always below the hump crest, which should be taken into account when studying rolling-down dynamics of cuts with varied length.

A review of experience in studying the hump yard performance shows that the rotating inertia of wheelsets should be taken into account in calculation of parameters for hump yards. This leads to a decrease in acceleration to values $g^{\prime}=\{9.11-9.65\} \mathrm{m} / \mathrm{s}^{2}[16,17]$. Both in Russia and abroad, weight and running performance of cuts are taken into account $[2,3]$. In addition, weight distribution within a cut of varied length is important for multicar cuts [18].

The proposed method for calculating the maximum number of cars in a cut $N_{\max }$ is based on the current safety principle of the classification process - the maximum kinetic energy of a cut $H_{\max }$ must not exceed the energy that can be absorbed by available hump retarders $H_{\text {ret }}$, i. e.:

$$
H_{\text {ret }} \geq H_{\max }
$$

There should be a possibility to retard a rolling-down cut of cars with all available hump retarder positions. The estimated exit speed of the cut to the classification track is limited to $1.38 \mathrm{~m} / \mathrm{s}$, which corresponds to the permissible impact velocity of cars on the railways of the Russian Federation.

This case can be described by the following expression: 


$$
h_{\mathrm{diff}}+h_{0}=h_{w}+H_{\mathrm{ret}}+h_{\mathrm{end}},
$$

where $h_{\text {diff }}$ is the difference between elevation of the hump crest and the minimum elevation of the end of the yard retarder position, $\mathrm{m} ; h_{0}$ is the specific energy corresponding to the initial running speed (shunting speed $=v_{o}, \mathrm{~m} / \mathrm{s}$ ), $\mathrm{MeV} ; h_{w}$ is the specific energy equivalent to the total work of uncontrolled forces of resistance to the movement of a multi-car cut, $\mathrm{MeV} ; h_{\mathrm{end}}$ is the specific energy corresponding to the end running speed in a given section $\left(v_{\mathrm{k}}=\right.$ no more than $\left.1.38 \mathrm{~m} / \mathrm{s}\right), \mathrm{MeV}$

Consequently:

$$
h_{\mathrm{diff}}+h_{0}-h_{w}-h_{\mathrm{end}}=H_{\mathrm{ret}} \text { or } h_{\mathrm{diff}}+h_{0}-h_{w}-h_{\mathrm{end}} \leq H_{\max } .
$$

Values $h_{\text {diff }}$ and $H_{\text {ret }}$ not depend on the number of cars in a cut. The power of hump retarders is determined by the following formula:

$$
H_{\text {ret }}=\left(0,5 \cdot n_{\text {ret }}^{R P-I} \cdot h_{\text {ret }}^{R P-I}+n_{\text {ret }}^{R P-I I} \cdot h_{\text {ret }}^{R P-I I}+n_{\text {ret }}^{Y R P} \cdot h_{\text {ret }}^{Y R P}\right) \cdot K_{\text {ret }},
$$

where 0.5 is the factor that takes into account the need of breaking down trains when one of the retarders in the first retarder position (RP-I) is switched off for scheduled maintenance and repair [2]; $n_{\text {ret }}^{R P-I}, n_{\text {ret }}^{R P-I I}, n_{\text {ret }}^{Y R P}$ is the number of retarders on retarder positions of the decreasing part (RP-I and RP-II) and in the classification yard (yard retarder position); $h_{\text {ret }}^{R P-I}, h_{r e t}^{R P-I I}, h_{\text {ret }}^{Y R P}$ is the available power per retarder placed on RP-I, RP-II and yard retarder position (YRP), respectively, $\mathrm{MeV} ; K_{\text {ret }}$ is the utilization factor of retarding facilities related to the location of retarder positions and the retarding characteristics of long cuts at which wheelsets cannot be squeezed out from retarders.

The number of cars in a cut and their weight are taken into account in calculating the specific energy corresponding to the speed of the cut $h_{v}$, as well as loss of energy consumed to overcome forces of resistance to the movement $h_{w}$. According to the current methodology, $h_{v}$ in general form is calculated by the following formula:

$$
h_{v}=\frac{v^{2}}{2 g^{\prime}}=\frac{v^{2}}{2 \cdot\left(1+0.42 \cdot \frac{n}{q}\right)},
$$

where $n$ is the number of axles in the cut; $q$ is the weight of the cut, tonnes.

In calculating the loss of energy consumed to overcome forces of resistance to movement $h_{w}$, the number of cars and weight of the cut should be taken into account [2]. According to the calculation method proposed by the authors, it is necessary to perform a number of iterative calculations to determine the maximum number of cars in a cut. Therefore, in order to calculate $H_{\max }$ (parameters $h_{\text {diff }}, h_{0}, h_{w}, h_{\mathrm{k}}$ ) and test condition 1 , it is necessary to simulate the rolling-down process [15].

When simulating the movement of the cut, projections of both accelerating and retarding forces on the rolling-down axle are taken into account. Axles of wheelsets are taken as application points of forces in the cut. In order to calculate car-to-car connections, all specific forces should be considered from car to car. Thus, when each car enters a particular section of the hump, several types of forces are applicable to this car. These include the specific driving force $(f)$, the net specific resistance $\left(w_{0}\right)$, resistance from switches and curves $\left(w_{\mathrm{sc}}\right)$, resistance from the environment and wind $\left(w_{\mathrm{ew}}\right)$, snow and frost $\left(w_{\text {sf }}\right)$, and retarder positions $\left(w_{\text {ret }}\right)$. 
Cars with uniformly distributed axle load are used for simulation. A point of separation of the cut from the approaching train is assumed to be a section of the moving part of the hump, which fulfills the following condition:

$$
v_{\text {cut }}>v_{\text {train }}
$$

where $v_{\text {cut }}$ is the running speed of the cut, $\mathrm{m} / \mathrm{s} ; v_{\text {train }}$ is the running speed of the approaching train, $\mathrm{m} / \mathrm{s}$.

In addition, the working zone of a yard conductor (uncoupling device) is taken into account, since the cut cannot be separated before the beginning of the uncoupling zone. The calculations were performed using the Skat-Otsep software package [15].

\section{Experimental data and results}

The object of the study is a real high-capacity hump yard, parameters of the layout and longitudinal section, and the power of retarding facilities that are used in the simulation.

Initially, the authors conduced a number of experiments to calculate the minimum required power of retarder positions, depending on the number of cars in a cut (Fig. 1). The minimum required power should be sufficient to stop a cut of loaded cars at the exit from the yard retarder. The calculation was performed for favorable rolling-down conditions:

- rolling-down route: "easy" track of a hump neck;

- maximum shunting speed: $2.5 \mathrm{~m} / \mathrm{s}$;

- the cut consists of full-weight loaded cars;

- climatic conditions: favorable;

- utilization factor of retarder positions: assumed to be 0.67 in accordance with the applicable guidelines [1].

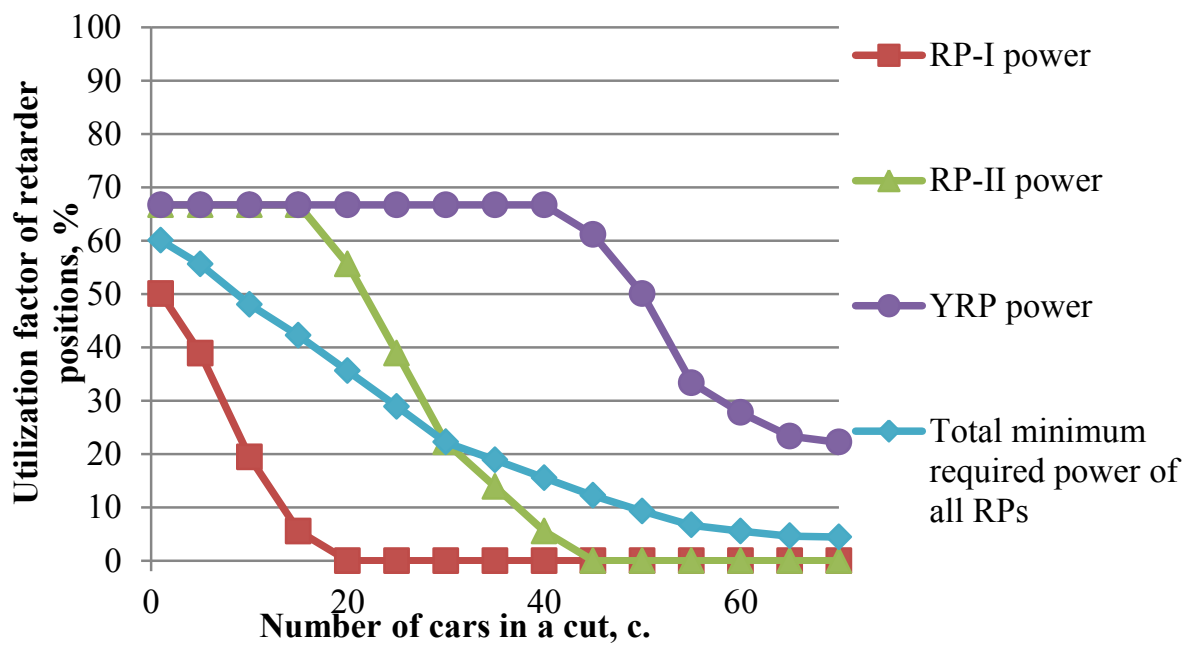

Fig. 1. Dependence of the required power of hump retarders on the number of cars in a cut.

The results of the experiment show that the required power level of retarder positions decreases with an increase in the number of cars in a cut. This effect can be attributed to a distribution pattern of cut weight in the vertical plane: the conditional center of mass of the entire cut decreases relative to the hump crest with an increase in the number of cars in the 
cut (Fig. 2). Therefore, the total specific energy stored by the cut decreases with an increase in the number of cars.

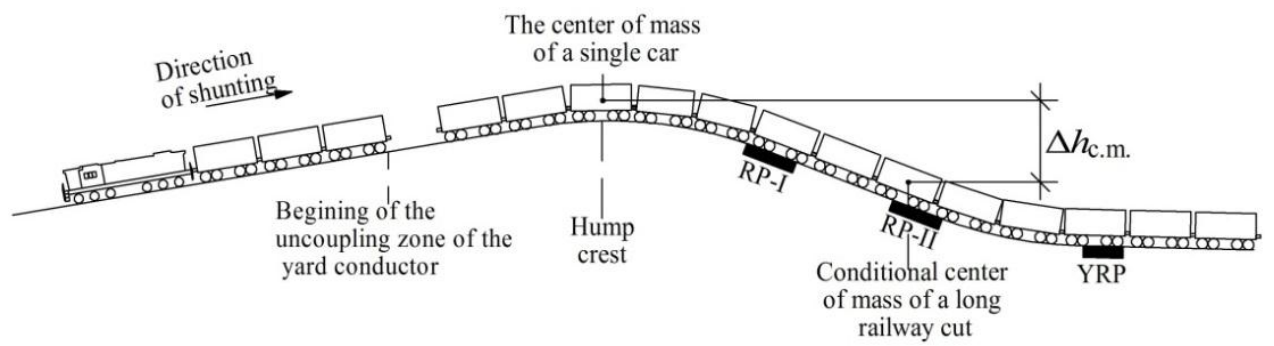

Fig. 2. Schematic diagram for determining the conditional center of mass of the cut with several cars.

At the second stage, the authors conducted experiments by rolling down cuts of empty cars with the worst running properties. Cuts were rolled down without retardation. During the simulation, the exit speed of the cut from the yard retarder position $\left(v_{\text {exit }}\right)$ and the probability that the cut will overcome the yard retarder position $\left(P_{\text {exit }}\right)$ were determined (Table 1). The experiments were performed for the following conditions:

- rolling-down route: "difficult" track of a hump neck;

- climatic conditions: severe;

- net specific resistance to the movement of a single very bad runner: $4.5 \mathrm{~N} / \mathrm{kN}$;

- the net specific resistance to the movement of a single-car cut is assumed to be moderate for the lightweight category $(1.75 \mathrm{~N} / \mathrm{kN})$;

- the net specific resistance to the movement of a multi-car cut is derived from the distribution law of a random variable for cars of the lightweight category [2];

- the probability $\left(P_{\text {exit }}\right)$ that the last car in the cut will overcome the yard retarder position is determined by repeated simulation of the rolling-down process for various multicar cuts of the lightweight category with a specified length;

- the average exit speed from the yard retarder position is determined by simulating the rolling-down process for various multi-car cuts of the lightweight category, unless the cuts fail to reach a target point.

The values in Table 1 suggest that the probability that the cut of cars will overcome the yard retarder position in a given hump ( $\left.P_{\text {exit }}\right)$ begins to decrease for cuts with 40 cars and more. Therefore, cuts with more than 40 cars is subject to risk of being stopped on the decreasing part of the hump. This may interrupt hump yard operations and increase the probability of incidents, including collisions between cars at high speeds.

Table 1. The average exit speed of empty cars from the yard retarder position, rolling down without retardation.

\begin{tabular}{|c|c|c|c|c|c|c|c|c|c|c|c|c|}
\hline \multirow{3}{*}{$\begin{array}{c}v_{\text {shunt }}, \\
\mathrm{m} / \mathrm{s}\end{array}$} & \multicolumn{12}{|c|}{ Number of cars in a cut } \\
\hline & \multicolumn{2}{|c|}{$\begin{array}{c}\text { A very bad } \\
\text { runner }\end{array}$} & \multicolumn{2}{|c|}{1} & \multicolumn{2}{|c|}{30} & \multicolumn{2}{|c|}{40} & \multicolumn{2}{|c|}{50} & \multicolumn{2}{|c|}{60} \\
\hline & $P_{\text {exit }}$ & $\begin{array}{l}v_{\text {exit }}, \\
\mathrm{m} / \mathrm{s}\end{array}$ & $P_{\text {exit }}$ & $\begin{array}{l}v_{\text {exit }}, \\
\mathrm{m} / \mathrm{s}\end{array}$ & $P_{\text {exit }}$ & $\begin{array}{l}v_{\text {exit }}, \\
\mathrm{m} / \mathrm{s}\end{array}$ & $P_{\text {exit }}$ & $\begin{array}{l}v_{\text {exit }}, \\
\mathrm{m} / \mathrm{s}\end{array}$ & $P_{\text {exit }}$ & $\begin{array}{l}v_{\text {exit }}, \\
\mathrm{m} / \mathrm{s}\end{array}$ & $P_{\text {exit }}$ & $\begin{array}{l}v_{\text {exit }}, \\
\mathrm{m} / \mathrm{s}\end{array}$ \\
\hline 1.0 & 1.00 & 1.79 & 1.00 & 4.30 & 1.00 & 2.61 & 0.98 & 1.30 & 0.09 & 0.58 & 0.00 & - \\
\hline 1.5 & 1.00 & 1.90 & 1.00 & 4.35 & 1.00 & 2.70 & 1.00 & 1.48 & 0.26 & 0.59 & 0.00 & - \\
\hline 2.0 & 1.00 & 2.05 & 1.00 & 4.42 & 1.00 & 2.89 & 1.00 & 1.84 & 0.71 & 0.87 & 0.00 & - \\
\hline 2.5 & 1.00 & 2.23 & 1.00 & 4.53 & 1.00 & 3.09 & 1.00 & 2.17 & 0.98 & 1.26 & 0.25 & 0.64 \\
\hline
\end{tabular}

Table 2 shows the results of similar experiments for cuts of loaded cars. The calculation is based on the same conditions with the following exceptions: 
- the net specific resistance to the movement of a single very good runner is assumed to be minimum for the heavyweight category of cars $(0.5 \mathrm{~N} / \mathrm{kN})$;

- the net specific resistance to the movement of a single-car cut is assumed to be moderate for the heavyweight category of cars $(1.25 \mathrm{~N} / \mathrm{kN})$;

- the net specific resistance to the movement of a multi-car cut is derived from the distribution law of a random variable for cars of the heavyweight category [2];

- the probability that the last car in the cut overcomes the yard retarder position is determined by repeated simulation of the rolling-down process for various multi-car cuts of the heavyweight category with a specified length;

- the average exit speed from the yard retarder position is determined by simulating the rolling-down process for various multi-car cuts of the heavyweight category, unless the cuts fail to reach a target point.

Table 2. The average exit speed of loaded cars from the yard retarder position, without retarding at all retarder positions.

\begin{tabular}{|c|c|c|c|c|c|c|c|c|c|c|c|c|}
\hline \multirow{3}{*}{$\begin{array}{c}v_{\text {shunt }}, \\
\mathrm{m} / \mathrm{s}\end{array}$} & $\begin{array}{c}|c| \\
\text { A very good } \\
\text { runner }\end{array}$ & \multicolumn{2}{|c|}{1} & \multicolumn{2}{|c|}{30} & \multicolumn{2}{c|}{40} & \multicolumn{2}{|c|}{50} & \multicolumn{2}{c|}{60} \\
\cline { 2 - 14 } & $P_{\text {exit }}$ & $\begin{array}{c}v_{\text {exit }}, \\
\mathrm{m} / \mathrm{s}\end{array}$ & $P_{\text {exit }}$ & $\begin{array}{c}v_{\text {exit }}, \\
\mathrm{m} / \mathrm{s}\end{array}$ & $P_{\text {exit }}$ & $\begin{array}{c}v_{\text {exit }}, \\
\mathrm{m} / \mathrm{s}\end{array}$ & $P_{\text {exit }}$ & $\begin{array}{c}v_{\text {exit, }} \\
\mathrm{m} / \mathrm{s}\end{array}$ & $P_{\text {exit }}$ & $\begin{array}{c}v_{\text {exit, }} \\
\mathrm{m} / \mathrm{s}\end{array}$ & $P_{\text {exit }}$ & $\begin{array}{c}v_{\text {exit, }} \\
\mathrm{m} / \mathrm{s}\end{array}$ \\
\hline 1.0 & 1.00 & 7.35 & 1.00 & 6.93 & 1.00 & 4.80 & 1.00 & 4.09 & 1.00 & 3.56 & 1.00 & 3.11 \\
\hline 1.5 & 1.00 & 7.38 & 1.00 & 6.99 & 1.00 & 4.89 & 1.00 & 4.20 & 1.00 & 3.68 & 1.00 & 3.27 \\
\hline 2.0 & 1.00 & 7.46 & 1.00 & 7.09 & 1.00 & 5.02 & 1.00 & 4.37 & 1.00 & 3.87 & 1.00 & 3.48 \\
\hline 2.5 & 1.00 & 7.55 & 1.00 & 7.16 & 1.00 & 5.17 & 1.00 & 4.55 & 1.00 & 4.08 & 1.00 & 3.72 \\
\hline
\end{tabular}

The data in Table 2 suggest that cuts of loaded cars are not subject to any limitation in terms of the number of cars. Therefore, shunting of multi-car loaded cuts can be performed without limiting the number of cars in a cut.

\section{Conclusion}

This paper proposes a new method for calculating the maximum number of cars in a cut based on probability calculations and simulation modeling of the shunting process in hump yards. The findings show that the maximum number of cars in a cut depends on the longitudinal section and equipment of a hump yard, as well as on climatic conditions of the area where it is located. In this case, shunting of loaded multi-car cuts to a clear classification track is not subject to any restriction on length of a cut.

It has been established that the permissible number of cars in a cut can be limited by the total kinetic energy stored by an empty multi-car cut, rather than by the required power level of hump retarders. Therefore, in addition to checking the power of hump retarders, it is necessary to check rolling down of cuts with empty cars to the classification yard (outside the yard retarder position). The proposed method of calculation is more advanced than the method currently used on the railways of the Russian Federation and a number of other countries. By using the proposed method, it is possible to increase or even remove the restriction on the maximum number of cars in a cut, which should be calculated for each specific hump yard. 


\section{References}

1. Instrukcija po raschetu maksimal'no dopustimoj dliny otcepa pri rospuske na sortirovochnyh gorkah [Instructions on calculating the maximum allowable length of the uncoupling by disbanding on the hump yards] (Moscow, 2012). (in Russian)

2. Pravila i normy proektirovanija sortirovochnyh ustrojstv na zheleznyh dorogah kolei $1520 \mathrm{~mm}$ [Rules and design standards for assorting works on railways with track 1520 $\mathrm{mm}$ ] (Tehinform, Moscow, 2003). (in Russian)

3. M. Kutz, Handbook of transportation engineering (McGraw-Hill Professional, Boston, 2004).

4. E.R. Kraft, Journal of Transportation Research Forum, Vol. 39 (4), 95-115 (2000).

5. H. Khadilkar, S.K. Sinha, Proceedings of the International Conference on Industrial Engineering and Engineering Management, 1151-1155 (IEEE, Bali, 2016).

6. K. Kube, Progressive Railroading, 7, 50-52 (2002).

7. P. Logan, Role of Yard or Terminal in Operating Performance and Capacity (Transportation Research Board, Washington D.C., 2006).

8. J. Prokop, Sh. Myojin, Memoirs of the Faculty of Engineering, Vol. 27, 41-58 (1993).

9. G. Ribeill, La Vie du Rail, 3529, 13-25 (2015).

10. J.T. Haahr, R.M. Lusby, Networks, Vol. 67 (2), 126-138 (2016).

11. J.T. Haahr, R.M. Lusby, A Matheuristic Approach for Solving the Railroad Hump Yard Block-to-Track Assignment (DTU Management Engineering, 2015).

12. Z. Wang, A. Ceder, Journal of the Operational Research Society, 1, 1600-1619 (2017).

13. M. Rhodes, German Marshalling Yard Directory (Blurb, Incorporated, 2016).

14. A.A. Gunbin, The Siberian Transport University Bulletin, 1 (44), 5-14 (2018). (in Russian)

15. A.A. Klimov, A.A. Gunbin, Scientific problems of transportation in Siberia and the Far East, 2, 88-91 (2011). (in Russian)

16. S.A. Bessonenko, Doctoral thesis, Moscow State University of Railway Engineering, Moscow, 2011. (in Russian)

17. V.I. Bobrovskiy, D.N. Kozachenko, Sbornik nauchyh trudov GETUT [Collection of scientific papers of Kyiv University of Economics and Transport Technologies], Vol. 16, 20-29 (2010). (in Ukraine)

18. V.I. Bobrovskiy, D.N. Kozachenko, N.P. Bozhko, N.V. Rogov, N.I. Berezovy, A.V. Kudryashov, Optimizacija rezhimov tormozhenija otcepov na sortirovochnyh gorkah [Optimization of uncoupling braking modes on the hump yard] (Makoveckiy Pabl., Dnepropetrovsk, 2010). (in Ukraine) 